\title{
Effect of heat treatment on the tribological performance of electroless quaternary nickel alloy
}

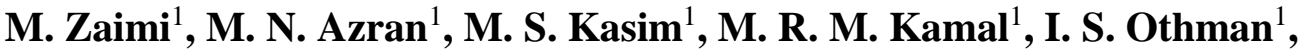

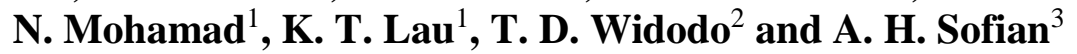 \\ ${ }^{1}$ Fakulti Kejuruteraan Pembuatan, Universiti Teknikal Malaysia Melaka, \\ Hang Tuah Jaya, 76100 Durian Tunggal, Melaka, Malaysia. \\ "Email: mdzaimi@utem.edu.my \\ Phone: +6011-14310750; Fax: +609424222 \\ ${ }^{2}$ Department of Mechanical Engineering, Brawijaya University, \\ Malang, Street Mayjend Haryono 167 Malang 65145 Indonesia. \\ ${ }^{3}$ Faculty of Chemical and Natural Resources Engineering, Universiti Malaysia Pahang, \\ 26300, Gambang, Kuantan, Pahang, Malaysia.
}

\begin{abstract}
Heat treatment of nickel-based alloy can increase the alloy's hardness as well as the wear resistance properties. Nevertheless, the effect of heat treatment on the quaternary Ni alloy coating properties produced from electroless deposition bath is less known due to its composition uniqueness. In this study, $\mathrm{Cu}$ and $\mathrm{Co}$ are added in the Ni-P alloy matrix using hypophosphite-based Electroless Ni deposition method on mild steel substrate in acidic and alkaline bath. The coatings are then heat treated at $623 \mathrm{~K}$ for 3600s. The coatings hardness is measured using microVickers hardness tester and the surface morphology of the coatings are studied using both Scanning Electron Microscope (SEM) and X-ray diffraction (XRD) analysis. X-ray fluorescence (XRF) measurement is used to measure the coatings compositions. The wear behavior of the coatings is also investigated before and after heat treatment using ASTM G-99. The coatings from acidic-based bath produces Ni-Cu-Co-P alloy coating while the alkaline-based bath produces $\mathrm{Ni}-\mathrm{Co}-\mathrm{Cu}-\mathrm{P}$ alloy based on XRF analysis. Results show that the hardness increases more than $20 \%$ for acidic-based bath and $40 \%$ for alkaline-based bath coating. The highest increment is the Ni-Co-Cu-P alloy, from 553.3 HV to $991.3 \mathrm{HV}$ after heat treatment. The grain refinement of the coatings can be observed after heat treatment in SEM observation. This is proved by the XRD measurement results where polycrystalline $\mathrm{Ni}$ (111) formation is seen after heat treatment overshadowing the $\mathrm{Cu}$ (111) and $\mathrm{Co}$ (111) peaks. Ni phosphide species are also formed after the heat treatment. The polycrystalline $\mathrm{Ni}$ and the $\mathrm{Ni}$ phosphide formation, as well as the existence of $\mathrm{Co}$ and $\mathrm{Cu}$ in the alloy deposits reduces the wear rate significantly after the heat treatment.
\end{abstract}

Keywords: Electroless Ni deposition; quaternary Ni alloy; tribology; heat treatment; wear rate. 


\section{INTRODUCTION}

The autocatalytic reaction in the electroless nickel deposition provides uniform deposition on a various type and complex shape of substrate. This made electroless nickel deposition become one of the common deposition method in various field such as electronic, automotive and chemical [1]. Ni-P alloy can be formed by hypophosphite-based bath which provide superior mechanical and tribological properties compare to pure $\mathrm{Ni}$ itself. Moreover, the plating bath can be modified by adding other metal ions such as $\mathrm{Cu}$, Co and $\mathrm{W}$, to further enhanced the abovementioned properties. The improvement of the mechanical and tribological properties of the $\mathrm{Ni}$ alloys also makes the coating potential to be used as a cutting tool. Conventional cutting tool inserts usually uses tungsten carbide as a substrate and multiple layers Ti-based alloy deposited by pressure vapor deposition which is quite expensive in terms of coating equipment investment and, it's limitations.

Coatings for cutting tools also can be made from abrasive coatings. The formation of composite $\mathrm{Ni}$ coatings also can be achieved by adding abrasive particle such as $\mathrm{SiC}$, which significantly increases its hardness more than 30\% [2]. However, the deposition method requires surfactant to stabilize the deposition reaction, where the existence of foreign particle inside the plating bath solution will destabilize the deposition reaction itself [2]. Light metal composite such as $\mathrm{MgSiCp}$ reinforced aluminium alloy also has the potential to be used as abrasive materials [3]. Nevertheless, the process to form the composite requires superheating the aluminium alloy at $750^{\circ} \mathrm{C}$ which made the forming process expensive, dangerous and sensitive to normal atmosphere. The ternary and quaternary $\mathrm{Ni}$ alloy could be the cheaper alternative to coat on a less hard and cheap materials like mild steel. Balaraju et. al. proved that the as-plated Ni-Cu-P, Ni-W-P and Ni-Cu-W-P alloy have at least 5\% increment of hardness compare to Ni-P alloy [4]. With heat treatment at $400^{\circ} \mathrm{C}$, the hardness of all as abovementioned $\mathrm{Ni}$ alloy improve significantly, almost double compare to the as-plated coatings [4]. The Ni alloy coatings hardness after heat treatment is near to $900 \mathrm{HV}$, comparable to conventional high-speed steel hardness in between 740 to $870 \mathrm{HV}$ for noncobalt based and 870 to $1000 \mathrm{HV}$ for cobalt based steels [5]. The heat treatment temperature for the Ni-P to gain maximum hardness is between $300^{\circ} \mathrm{C}$ to $400^{\circ} \mathrm{C}$ [6].

The wear profile of a cutting tool is highly related to temperature during turning, however, it requires special tools to measure the temperature. The estimated temperature during turning of a mild steel substrate is less than $100^{\circ} \mathrm{C}$, hence, the use of $\mathrm{Ni}$ alloy coating for cutting is considered feasible without significant change of the coating microstructure [7]. The Ni-W-P alloy $(\sim 500 \mathrm{HV})$ deposited tungsten carbide cutting tool insert cutting performance was done by Sanusi et. al. for cutting tool recycling [8]. However, the results showed the coating is completely removed after one minute, thus, the wear analysis of the $\mathrm{Ni}$ alloy coating as a cutting tool in either milling or turning are not feasible for relatively soft coatings. Therefore, the method of pin-on-disk is suitable to be used to evaluate Ni alloy coatings as per ASTM G-99-05(2010) [9]. In the previous studies, the addition of Co (II) and $\mathrm{Cu}$ (II) ions in the hypophosphite-based electroless $\mathrm{Ni}$ deposition bath can produces a quaternary $\mathrm{Ni}-\mathrm{Cu}-\mathrm{Co}-\mathrm{P}$ and $\mathrm{Ni}-\mathrm{Co}-\mathrm{Cu}-\mathrm{P}$ alloy depending on plating bath $\mathrm{pH}$ [10-12]. The abovementioned coating is potential to be used as a hard coating with high corrosion resistance in neutral media. Still, the wear properties of the coatings before and after heat treatment are yet to be studied. 
In this study, the quaternary $\mathrm{Ni}$ alloy is deposited using hypophosphite-based electroless $\mathrm{Ni}$ deposition bath. The $\mathrm{Cu}$ (II) and $\mathrm{Co}$ (II) ions are added in the bath. The deposition time is set to $3600 \mathrm{~s}$ with magnetic bar agitation at $358 \pm 2 \mathrm{~K}$. The substrate used is mild steel, etched with diluted hydrochloric acid. The coated sample is then heat-treated at $623 \mathrm{~K}$ for $3600 \mathrm{~s}$. Comparison is made between the non-heat-treated and heat-treated samples in terms of surface morphology, hardness and wear properties. The composition analysis is based on the previous research [10-12]. The surface morphology and crystallinity are studied using scanning electron microscope (SEM) and X-ray diffraction (XRD) measurement respectively. The hardness of the sample is measured using microVickers hardness tester. Using pin-on-disk machine, the wear properties of the coatings are studied.

\section{METHODS AND MATERIALS}

Mild steel $(20 \mathrm{~mm} \times 20 \mathrm{~mm} \times 0.5 \mathrm{~mm})$ is used as substrates for electroless quaternary Ni alloy deposition. The mild steel substrates are polished using emery paper until \#1200 to produce a mirror-like surface. The substrates are then degreased with ethanol in ultrasonic bath before rinsed with distilled water. Surface activation of the substrates is done using diluted $\mathrm{HCl}$ aqueous solutions $(\mathrm{HCl}, 17.5 \%)$ for $30 \mathrm{~s}$. After surface activation, the substrates are rinsed heavily with distilled water again before immersing into electroless quaternary Ni alloy deposition bath with composition shown Table 1 . The electroless deposition parameter is stated in Table 2. The coated substrates are rinsed with distilled water and ethanol before testing. The detailed plating procedure is shown in Figure 1. Similar mild steel samples with $50 \mathrm{~mm}$ diameter are also undergone similar electroless deposition procedure for pin-on-disk testing. $\mathrm{Cu}$ (II) and $\mathrm{Co}$ (II) ions are used as metal ion additives. The $\mathrm{Cu}$ (II) ion is used lesser than other metal ions is due to its reaction inhibitor properties as per discussed in previous study [12].

Table 1. Plating bath composition of electroless quaternary Ni alloy deposition conditions on mild steel.

\begin{tabular}{lc}
\hline Plating bath composition & Concentrations \\
\hline Nickel Sulfate $\left(\mathrm{NiSO}_{4} \cdot 6 \mathrm{H}_{2} \mathrm{O}\right)$ & $0.10 \mathrm{M}$ \\
Sodium Hypophosphite Dihydrate $\left(\mathrm{NaH}_{2} \mathrm{PO}_{2} \cdot 2 \mathrm{H}_{2} \mathrm{O}\right)$ & $0.28 \mathrm{M}$ \\
Trisodium Citrate Dihydrate $\left(\mathrm{Na}_{3} \mathrm{C}_{6} \mathrm{H}_{5} \mathrm{O}_{7} \cdot 2 \mathrm{H}_{2} \mathrm{O}\right)$ & $0.20 \mathrm{M}$ \\
Ammonium Sulfate $\left(\left(\mathrm{NH}_{4}\right)_{2} \mathrm{SO}_{4}\right)$ & $0.50 \mathrm{M}$ \\
Cobalt Sulfate $\left(\mathrm{CoSO}_{4} \cdot 6 \mathrm{H}_{2} \mathrm{O}\right)$ & $0.01 \mathrm{M}$ \\
Copper(II) Sulfate Pentahydrate $\left(\mathrm{CuSO}_{4} \cdot 5 \mathrm{H}_{2} \mathrm{O}\right)$ & $0.001 \mathrm{M}$ \\
\hline
\end{tabular}


Table 2. Plating parameters of electroless quaternary Ni alloy deposition conditions on mild steel.

\begin{tabular}{lc}
\hline Parameters & Conditions \\
\hline Plating bath $\mathrm{pH}$ & $4.50,4.75,5.00,8.50$, \\
& $9.00,9.50$ \\
Bath temperature & $358 \pm 2 \mathrm{~K}$ \\
Deposition time & $3600 \mathrm{~s}$ \\
Agitation speed (magnetic bar) & $500 \mathrm{rpm}$ \\
\hline
\end{tabular}

The compositions of the electroless quaternary $\mathrm{Ni}$ alloy coating is measured using XRF (X-Supreme 8000, Oxford Instruments, United Kingdom). As for annealing, using a vacuum furnace, the temperature is increased from room temperature to $623 \mathrm{~K}$ in $900 \mathrm{~s}$ and maintained $623 \mathrm{~K}$ for $3600 \mathrm{~s}$. The temperature is then reduced to ambient normally. SEM (SEM EVO 50, Carl Zeiss SMT, United Kingdom) is used to observe the surface morphology of the coated substrates before and after annealing. The hardness and the wear behaviour of the coated substrate before and after annealing are studied using ASTM E92 MicroVickers Hardness Tester (HM-20 Series, Mitutoyo, Japan) and ASTM G-99 Pin-on-Disk Tester (TR20LE, Bangalore) respectively. The hardness test uses $0.1 \mathrm{~kg}$ force producing five indentations. As for the pin-on-disk test, $10 \mathrm{~N}$ loading is used on $6 \mathrm{~mm}$ diameter CR6 steel ball to rotate at $10 \mathrm{~mm}$ constant track radius with speed of $200 \mathrm{rpm}$ for $3600 \mathrm{~s}$. The schematic diagram for pin-on-disk testing is shown in Figure 2. The calculation of the wear rate $\left(\mathrm{mm}^{3} / \mathrm{min}\right)$ is based on the Equation (1) as per ASTM G-99. The XRD analyses is done on the coated substrate to investigate the effect of annealing on the surface crystallinity using glancing angle method with $\mathrm{CuK} \alpha$ incident angle of $0.5^{\circ}$, scanning from $10^{\circ}$ to $90^{\circ}$.

$$
\text { Wear volume, } V=2 \pi R\left[r^{2} \sin ^{-1}\left(\frac{d}{2 r}\right)-\left(\frac{d}{4}\right)\left(4 r^{2}-d^{2}\right)^{\frac{1}{2}}\right]\left[\mathrm{mm}^{3}\right]
$$

$R=$ wear track radius [mm], $r=$ pin end radius [mm], and $d=$ wear track width [mm] 

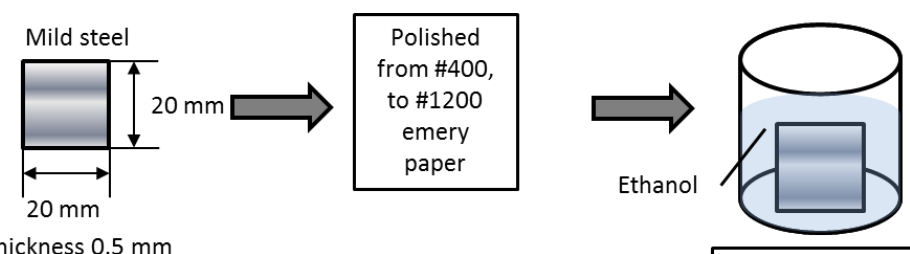

Ultrasonic bath

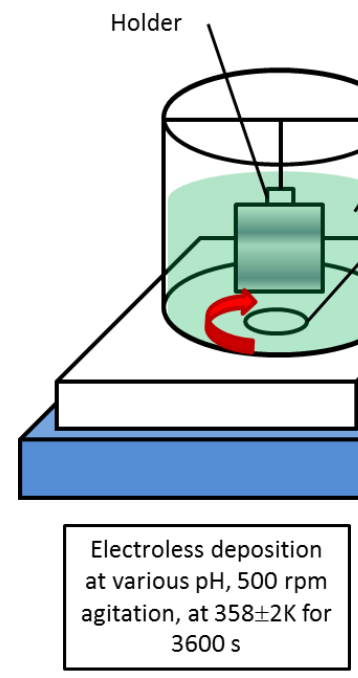

Plating bath solutions Magnetic bar

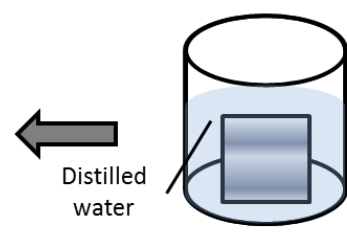

Rinsed heavily for $300 \mathrm{~s}$

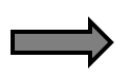

Distilled water

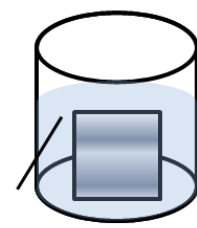

Rinsing

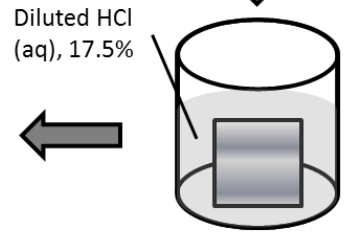

Surface activation, $30 \mathrm{~s}$ immersion
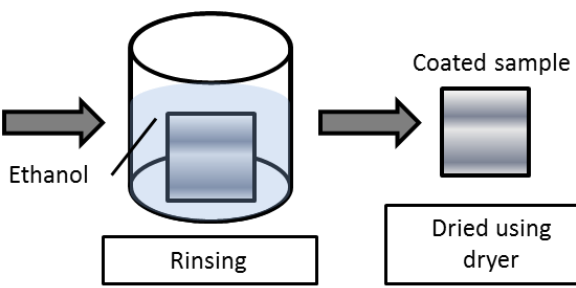

Dried using dryer

Figure 1. Electroless deposition on mild steel procedure.

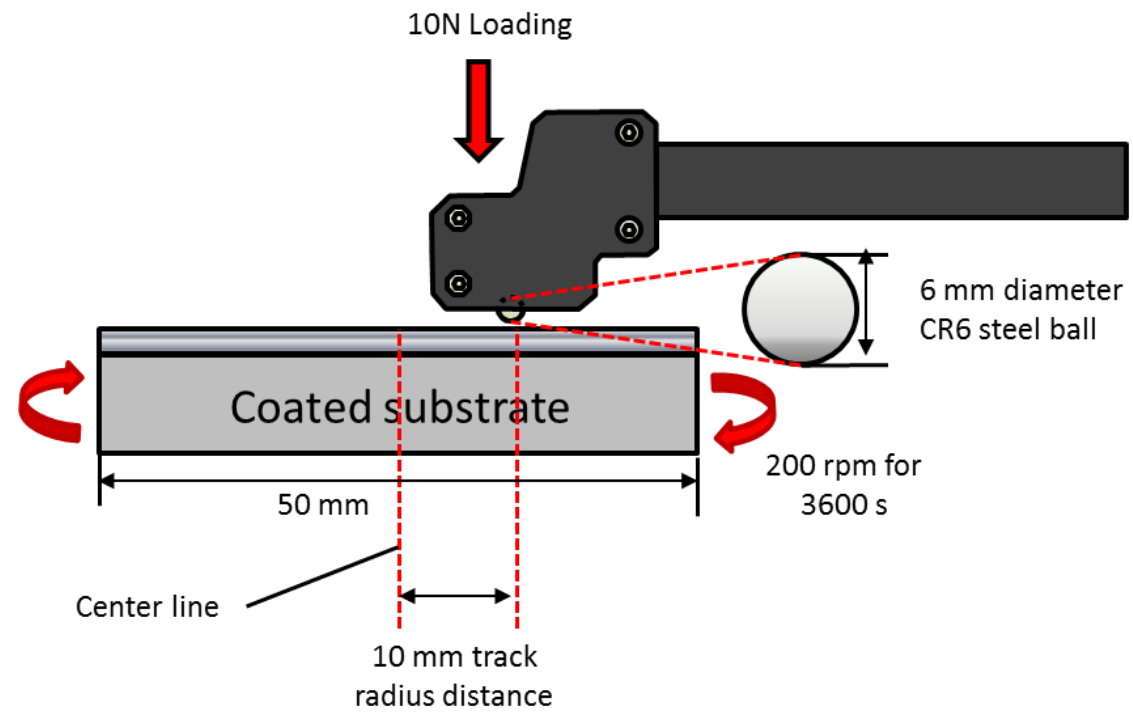

Figure 2. Pin-on-disk test. 


\section{RESULTS AND DISCUSSIONS}

The chemical composition by XRF analyses of the electroless quaternary Ni alloy coating on the mild steel is shown in Table 3. Average density of the coating is calculated based on the chemical composition. Using weight difference method, the weight difference of the substrates before and after electroless deposition are measured, divided by the surface area and average density to gain calculated thickness of the quaternary $\mathrm{Ni}$ alloy coating after 3600 $\mathrm{s}$ the electroless deposition. From Table 3, it can be observed that the deposition rate of the quaternary $\mathrm{Ni}$ alloy increases with the increase of plating bath $\mathrm{pH}$. The $\mathrm{Cu}$ content is relatively higher in coatings from acidic bath compare to alkaline bath due to $\mathrm{Cu}$ is easily deposited in acidic condition [12]. However, Co is much deposited in alkaline bath compare to $\mathrm{Cu}$ since $\mathrm{Cu}$ (II) ions act as inhibitor for the electroless deposition in alkaline condition due to more stable complex ion in alkaline compare to acidic condition [12].

Table 3. Chemical composition by XRF and calculated thickness of electroless quaternary $\mathrm{Ni}$ alloy coating on mild steel from various plating bath $\mathrm{pH}$ [11].

\begin{tabular}{lllllll}
\hline Bath pH & 4.50 & 4.75 & 5.00 & 8.50 & 9.00 & 9.50 \\
\hline $\mathrm{Ni}(\mathrm{wt} \%)$ & 68.55 & 82.09 & 74.42 & 83.53 & 88.73 & 91.09 \\
$\mathrm{Co}(\mathrm{wt} \%)$ & 1.32 & 1.39 & 1.52 & 11.60 & 7.54 & 5.79 \\
$\mathrm{Cu}(\mathrm{wt} \%)$ & 27.80 & 14.11 & 22.11 & 3.43 & 2.68 & 2.13 \\
$\mathrm{P}(\mathrm{wt} \%)$ & 2.33 & 2.42 & 1.96 & 1.44 & 1.06 & 1.00 \\
$\begin{array}{l}\text { Average density, } \rho \\
\left(\mathrm{g} / \mathrm{cm}^{3}\right)\end{array}$ & 8.76 & 8.74 & 8.78 & 8.82 & 8.83 & 8.84 \\
$\begin{array}{l}\text { Calculated thickness } \\
(\mu \mathrm{m})\end{array}$ & 3.29 & 4.18 & 5.60 & 24.97 & 35.54 & 43.61 \\
\hline
\end{tabular}

Table 4 exhibit the average hardness of the electroless quaternary Ni alloys before and after heat treatment. From the acidic bath, the Ni-Cu-Co-P alloy coatings on mild steel have the hardness comparable to its mild steel substrate at approximately $200 \mathrm{HV}$. This low hardness value is mainly contributed by the low coating thickness less than $6 \mu \mathrm{m}$. The heat treatment of the coatings from the acidic bath increase the hardness of the coatings gradually as the increase of the coatings from plating bath $\mathrm{pH} 4.50$ to $\mathrm{pH} 5.00$. The alkaline bath $\mathrm{pH}$ in otherwise, produces coatings higher than $20 \mu \mathrm{m}$. The increase of coatings thickness increases the coatings hardness, after heat treatment, the hardness increases more than $40 \%$ than the as-plated coatings. The highest of them all is the coatings from $\mathrm{pH} 9.50$ with the hardness of 991.3 higher than conventional high speed steel materials and even $\mathrm{SiC}$ embedded Ni-P coatings $[2,5]$. Hence, the coatings can be considered to be used as a cutting tool insert coatings. 
Table 4: Average micro hardness (HV) for the electroless quaternary Ni alloy on mild steel.

\begin{tabular}{lccc}
\hline Ni Alloy & $\mathrm{pH}$ & $\begin{array}{c}\text { Hardness before heat } \\
\text { treatment, HV }\end{array}$ & $\begin{array}{c}\text { Hardness after heat } \\
\text { treatment, HV }\end{array}$ \\
\hline & 4.50 & 210.7 & 254.6 \\
Ni-Cu-Co-P & 4.75 & 218.0 & 286.0 \\
& 5.00 & 233.6 & 325.5 \\
Ni-Co-Cu-P & 8.50 & 444.9 & 820.0 \\
& 9.00 & 521.1 & 901.5 \\
& 9.50 & 553.3 & 991.3 \\
\hline
\end{tabular}

The Figure 3 depicts the effect of heat treatment on the microstructure of the quaternary Ni alloys coatings. From the figure, the surface refinement of the coatings can be seen after heat treatment. The blackish lines on the surface of the coatings before heat treatment is alcohol residue after cleaning that appears during SEM observations. Other than that, all the coatings have uniform surface, absence of pit and without nodular-like structure as in Ni-P alloy [13].

Before the quaternary $\mathrm{Ni}$ alloy coatings undergo heat treatment, the XRD measurement results of all coatings show low intensity and broad peaks, resembling an amorphous-like structure in between $40^{\circ}$ to $50^{\circ}$ (Figure 4). Unlike electrodeposition method, the autocatalytic reaction of the electroless $\mathrm{Ni}$ alloy deposition produces uniform deposits on the substrate surface, and the $\mathrm{Co}, \mathrm{Cu}$ and $\mathrm{P}$ elements dispersed almost uniform distribution across the surface. This element distribution can be confirm using energy dispersive $\mathrm{X}$-ray (EDX) mapping analysis as shown in electroless Ni-Cu-Zn-P [14,15] and Ni-Cu-W-P alloy [4] deposits. 


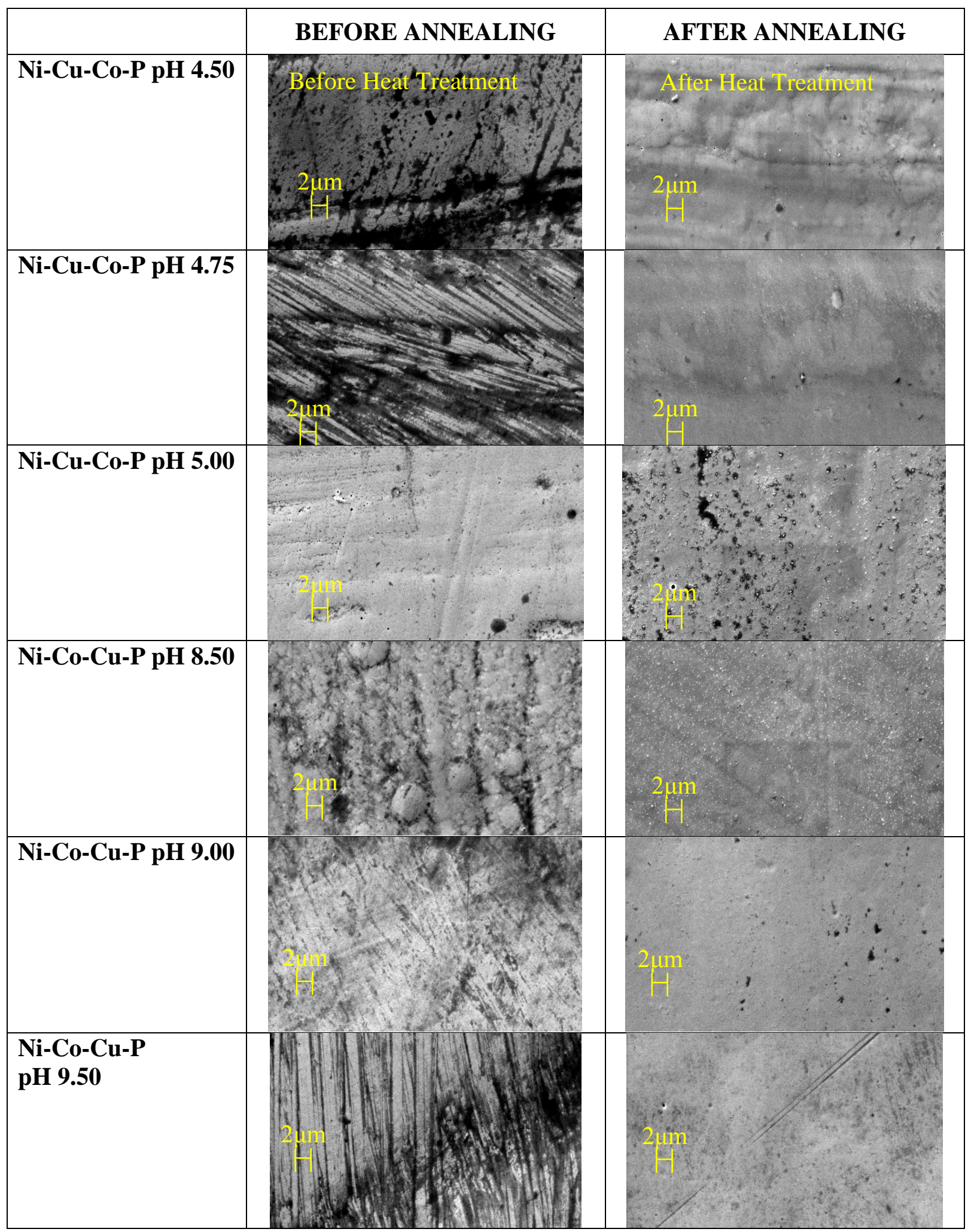

Figure 3. SEM micrograph of the electroless quaternary $\mathrm{Ni}$ alloy from various bath $\mathrm{pH}$ before and after annealing [20]. 


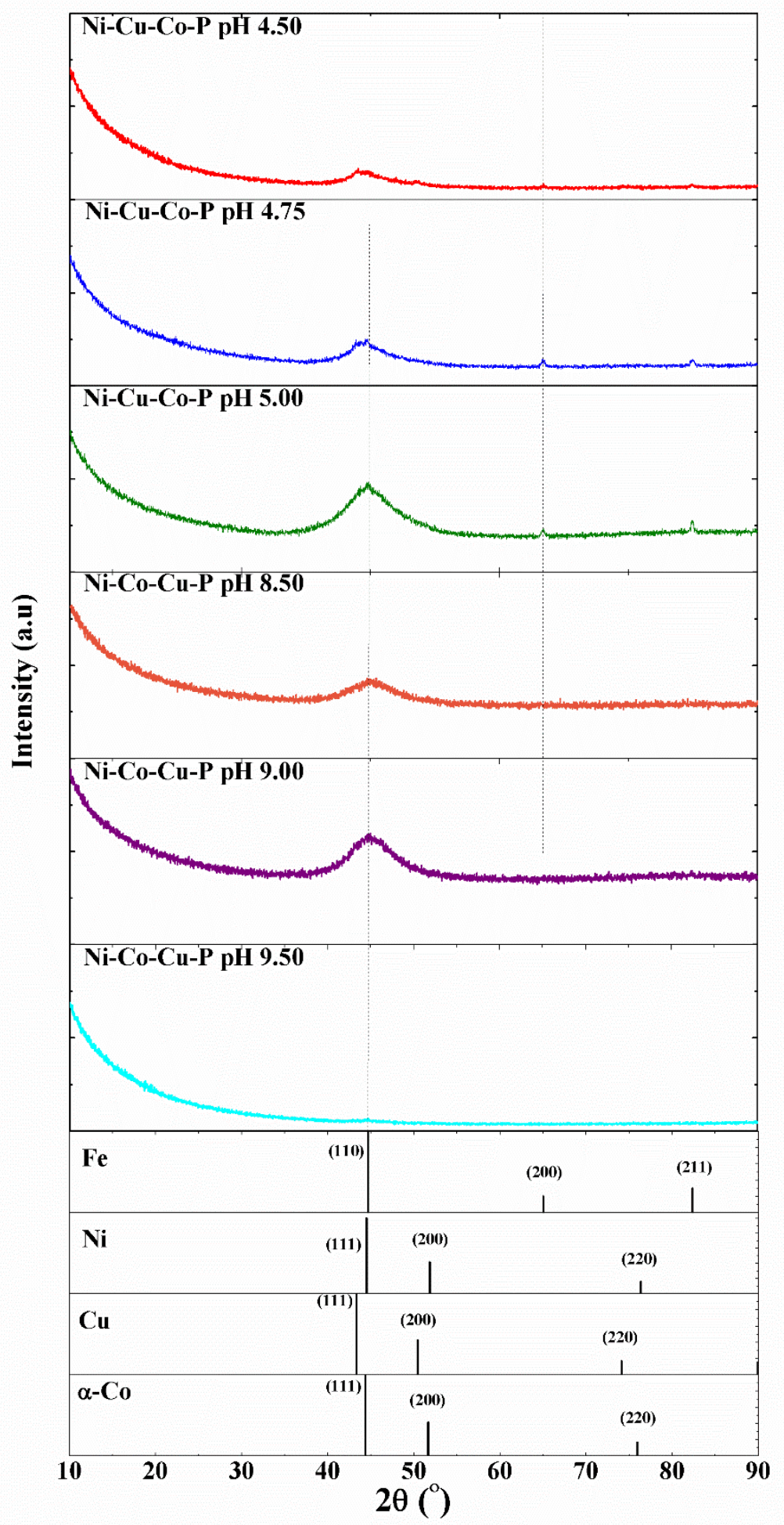

Figure 4. XRD analysis of electroless quaternary Ni alloy deposits before heat treatment. 


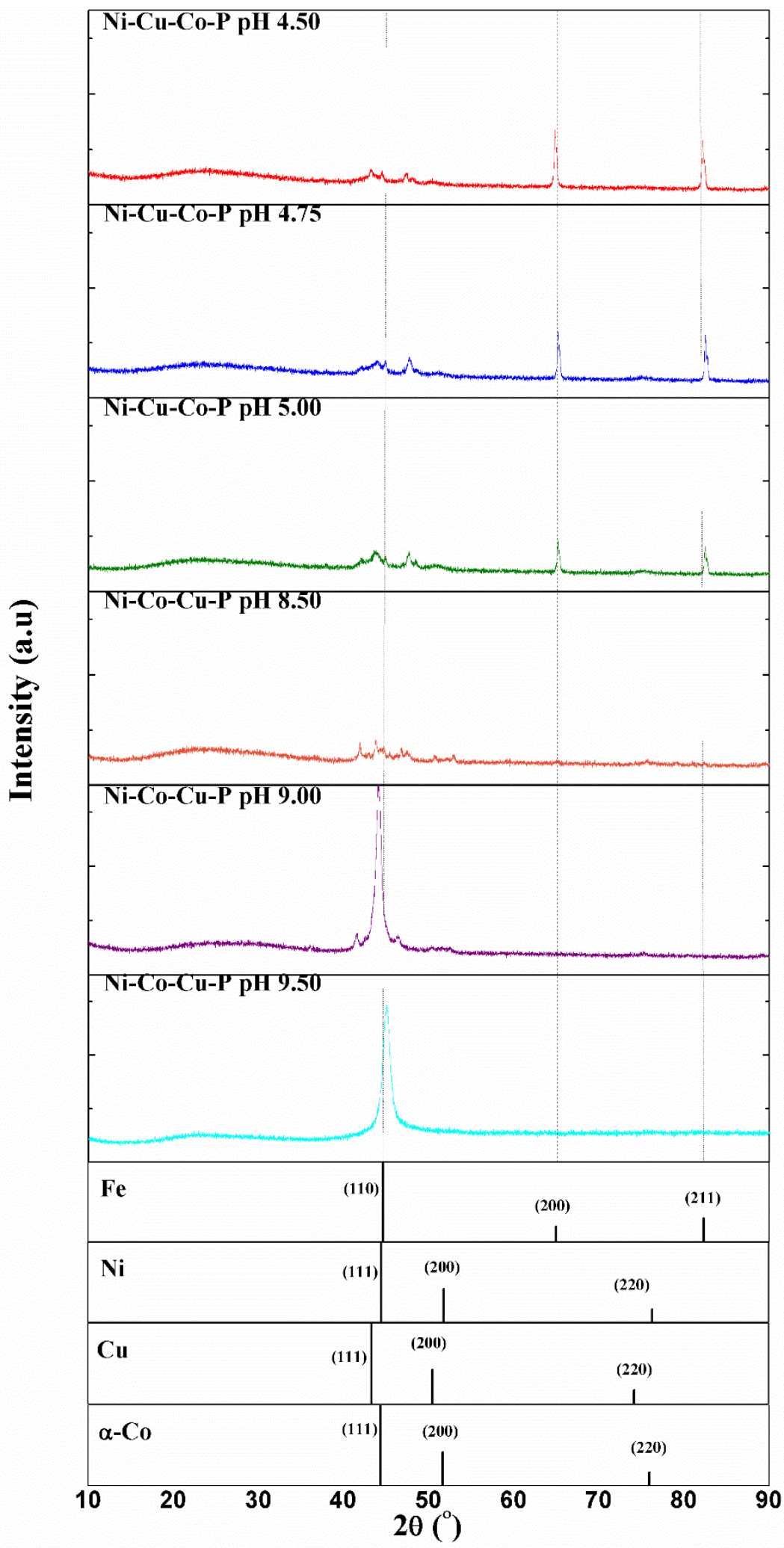

Figure 5. XRD analysis of electroless quaternary Ni alloy deposits after heat treatment. 
As the Ni quaternary $\mathrm{Ni}$ alloy heated at $623 \mathrm{~K}$, the elements in the coatings began to vibrate and segregate, producing higher crystallinity structure compare to non-treated coatings as shown in Figure 5. Since Ni content is the major content in all quaternary Ni alloy coatings, it can be suspected that during heat treatment at $623 \mathrm{~K}$, the originally amorphouslike structure of the quaternary Ni alloy surface as the XRD results in Figure 4, changed into polycrystalline $\mathrm{Ni}$ (111) near $44.48^{\circ}$ (standard pattern ICDD/PDF:01-071-4654) [16]. Nevertheless, the quaternary $\mathrm{Ni}$ alloy coatings the acidic bath has lower than $6 \mu \mathrm{m}$ thickness, the Fe (111) peaks from the mild steel substrate are detected at $44.67^{\circ}$ merging with $\mathrm{Ni}(111)$ peaks, as well as the other two peaks of Fe (200) and Fe (211) at $65.02^{\circ}$ and $82.33^{\circ}$ respectively (ICDD/PDF:00-006-0696). Moreover, the peaks before and after the Ni (111) peak can be considered as $\mathrm{Ni}$ phosphide species, $\mathrm{Ni}_{3} \mathrm{P}, \mathrm{Ni}_{2} \mathrm{P}$ and $\mathrm{Ni}_{12} \mathrm{P}_{5}$ alloy [17]. The peaks of the Ni phosphide species are being considered instead of copper phosphide and cobalt phosphide species due to the phosphorous is much co-deposited near $\mathrm{Ni}$ atom and $\mathrm{Ni}$ is the majority element in the coating itself $[18,19]$. The quaternary Ni alloy from the alkaline bath exhibits the similar Ni phosphide species peaks, except the peaks are gradually disappear when the deposit thickness becomes higher than $25 \mu \mathrm{m}$. At plating bath $\mathrm{pH} 9.50$, the high thickness of the electroless quaternary Ni alloy deposits cause more polycrystalline Ni (111) to be formed. The $\mathrm{Cu}(111)$ and $\mathrm{Co}(111)$ are less to be observed due to its $2 \theta$ value is very near to Ni (111) peak, thus, overshadowed by the Ni (111) peak.

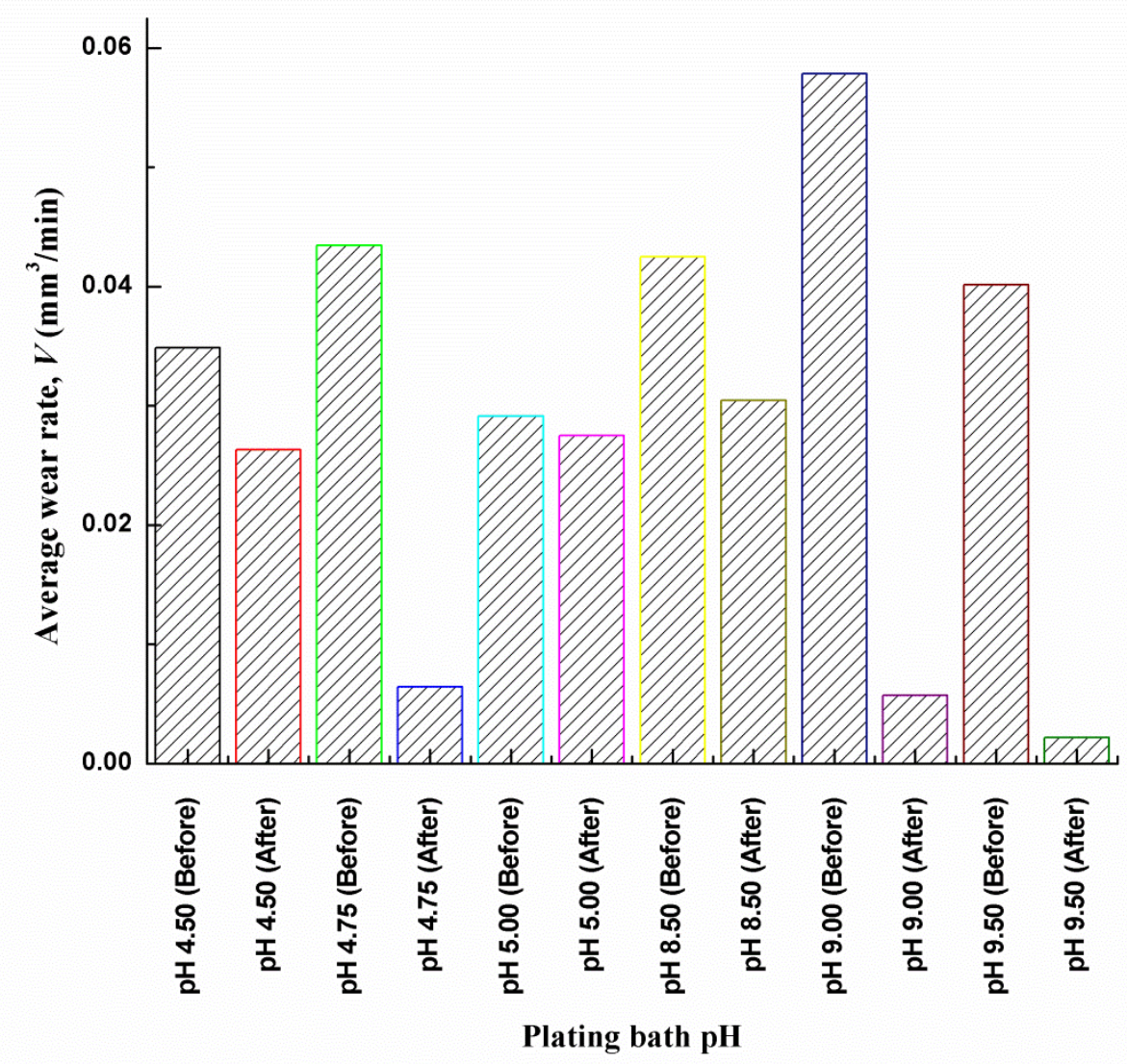

Figure 6. Average wear rate of electroless quaternary Ni alloy coatings before and after heat treatment. 
As in Figure 6, the wear rate of the as-plated and the heat treated electroless quaternary $\mathrm{Ni}$ alloy deposits are calculated using Equation (1) after pin-on-disk measurement. The hardness of the electroless quaternary $\mathrm{Ni}$ alloy can be related with its wear rate. The as-plated alloy deposits in respective of its plating bath $\mathrm{pH}$ is less harder than the heat-treated ally deposits, hence, the wear rate of the alloy is reducing drasticly, especially the deposits from plating bath $\mathrm{pH} 9.00$ and $\mathrm{pH} 9.50$. It also can be suggested the thicker deposits, and the higher Ni content in the alloy has the best improvement after heat treatment. Hence, the formation of the polycrystalline $\mathrm{Ni}$ (111) and Ni phosphide species as well as the $\mathrm{Cu}$ and $\mathrm{Co}$ addition can be the contributing factor in the improvement of wear rate. The alloy deposits from $\mathrm{pH} 9.50$ bath shows promising wear resistance performance comparable to Ni$\mathrm{P} / \mathrm{SiC}$ alloy composite [2].

Figure 7 and 8 are showing the coefficient friction of the electroless quaternary $\mathrm{Ni}$ alloy deposit surface before and after heat treatment. The as-plated quaternary Ni alloy deposits from the acidic bath shows lower coefficient friction compare to the alkaline bath (Figure 7). The higher coefficient friction of the alloy deposits from the alkaline bath is due to its higher thickness and hardness of the the deposits. After the heat treatment, the coefficient friction of the electroless quaternary $\mathrm{Ni}$ alloy with high $\mathrm{Ni}$ content in respective acidic and alkaline bath have the lowest value. Although in general, the coefficient friction of electroless $\mathrm{Ni}$ alloy is expected lower than $0.50 \mu$, the surface polishing during the initial process and the surface flatness may has influenced the coefficient friction, thus, higher value can be observed. Nevertheless, the coeffecient friction between the samples before and after heat treatment still in between 0.50 to $1.00 \mu$, except the range between maximum and minimum value of the coefficient friction are significantly reduced after heat treatment. Orginally, the electroless deposition provides a very uniform coating with uniform element distribution. The coefficient friction is expected to reduce aproximately in between 0.02 to 0.03 after heat treated at $573 \mathrm{~K}$ for $\mathrm{W}$-Co alloy [21], and in between 0.10 to $0.20 \mu$ for NiW-P alloy [22]. Hence, the formation of polycrystalline Ni (111) formation after heat treament at $623 \mathrm{~K}$ has very slight improvement of coefficient of the quaternary $\mathrm{Ni}$ alloy deposits surface. 


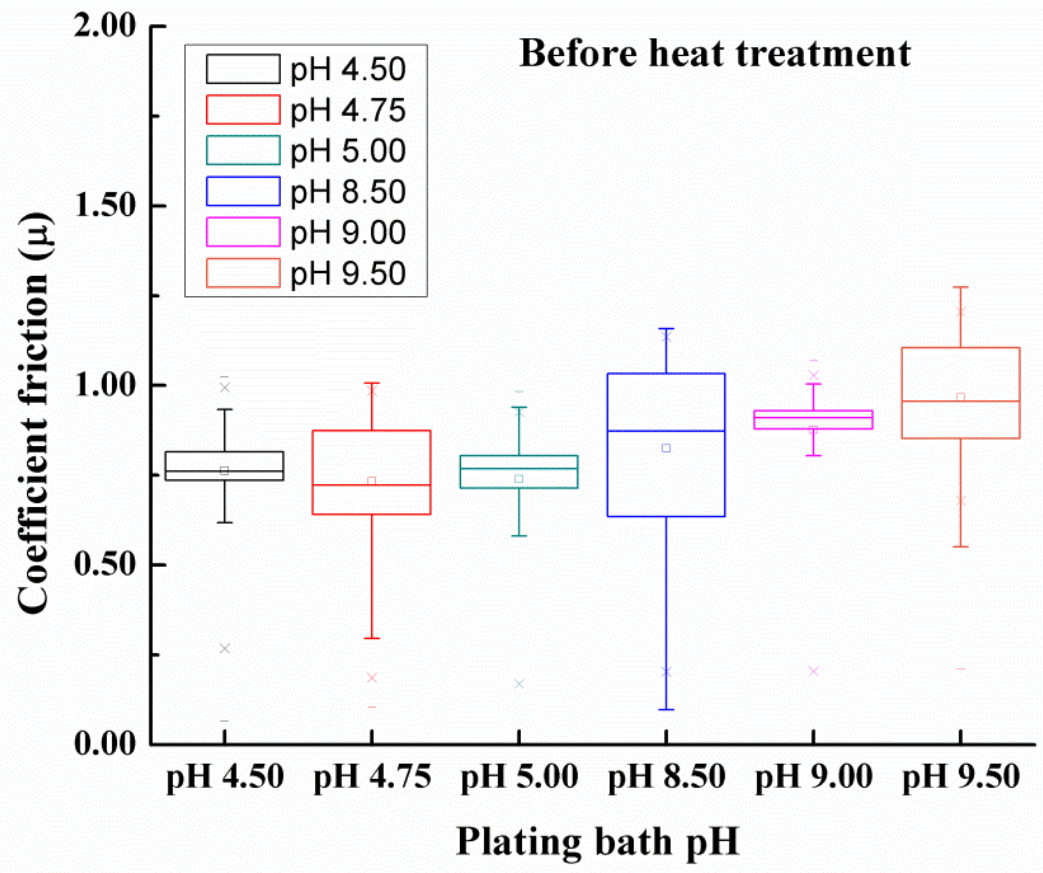

Figure 7. Coefficient friction of the electroless quaternary Ni alloy surface before heat treatment.

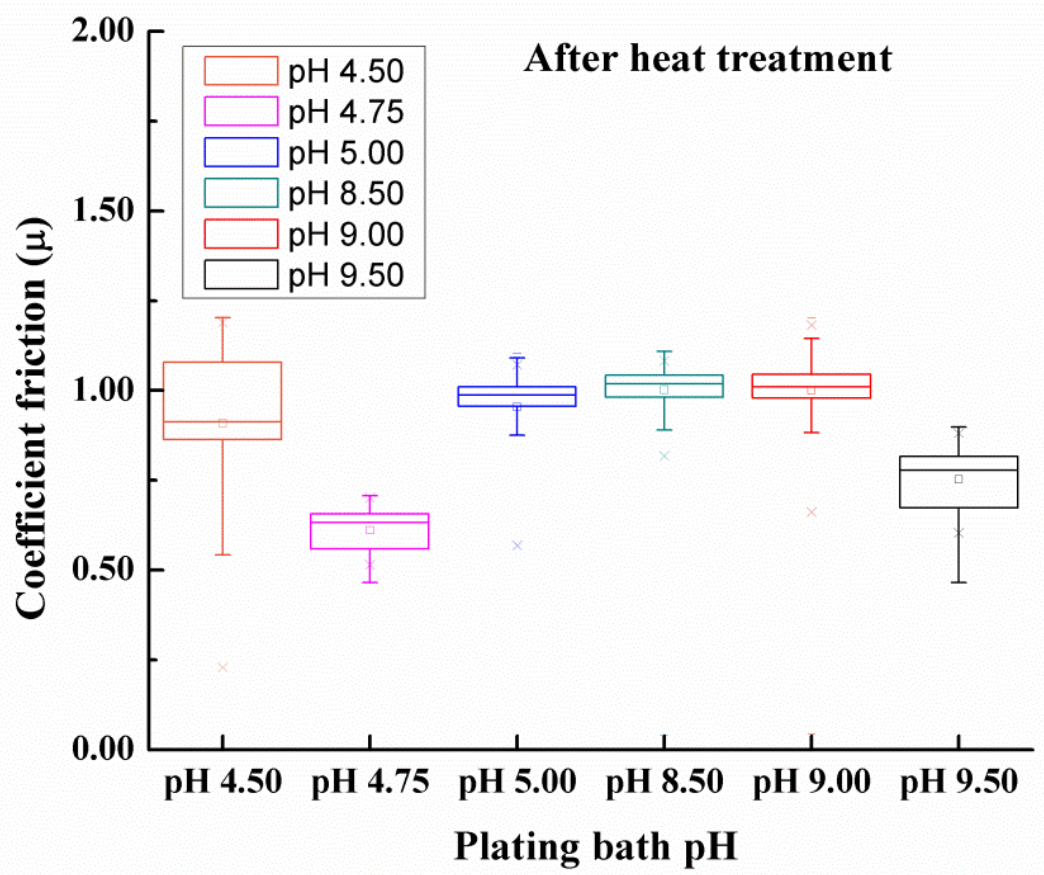

Figure 8. Coefficient friction of the electroless quaternary Ni alloy surface after heat treatment. 


\section{CONCLUSIONS}

The acidic bath bath produces a quaternary $\mathrm{Ni}-\mathrm{Cu}-\mathrm{Co}-\mathrm{P}$ alloy deposits, while the alkaline bath produces Ni-Co-Cu-P alloy deposits based on the XRF measurement results. The surface micro hardness of the as-plated electroless quaternary $\mathrm{Ni}$ alloy deposit increases gradually as the plating bath $\mathrm{pH}$ increases. The heat treatment of the quaternary $\mathrm{Ni}$ alloy improves the micro hardness significantly, at least $20 \%$ improvement for the alloy deposits from the acidic bath and more than $40 \%$ improvement of the alloy deposits from the alkaline bath. The micro hardness of the quaternary Ni alloy deposits from $\mathrm{pH} 9.50$ is $991.3 \mathrm{HV}$, can be considered better than conventional high-speed steel micro hardness. The grain refinement was observed in electroless quaternary $\mathrm{Ni}$ alloy deposits after heat treatment at $623 \mathrm{~K}$ for $3600 \mathrm{~s}$. The as-plated alloy deposits shows a broad and low intensity peaks near Ni (111) peak. The heat treated alloy deposits exhibits sharper polycrystalline Ni (111) peak along with Ni phosphide species peaks. The $\mathrm{Cu}$ (111) and Co (111) peaks are overshadowed by the majority content of $\mathrm{Ni}$ (111) peaks. The wear resistance of the electroless quaternary Ni alloy deposits improves significantly after heat treatment, especially the alloy deposits from $\mathrm{pH}$ 9.00 and 9.50 bath. Hence, the polycrystalline $\mathrm{Ni}$ and $\mathrm{Ni}$ phosphide species formation, as well as the $\mathrm{Co}$ and $\mathrm{Cu}$ content, have significant effect on the wear rate reduction. The coefficient friction of the alloy deposits is less affected by the heat treatment, but more affected by the Ni content, polycrystalline Ni of the alloy deposits. From these results, it can be suggested that the quaternary Ni alloy deposits can be considered as a cutting tool hard coating.

\section{ACKNOWLEDGEMENTS}

Thanks to the fellow researchers and technical staff from Carbon Research Technology, research group of the Advanced Manufacturing Centre in Faculty of Manufacturing, Universiti Teknikal Malaysia Melaka. In addition, the author would like to express gratitude to both members from Universiti Malaysia Pahang and Brawijaya University for their contributions. Special thanks to the Malayia's Ministry of Higher Education and Universiti Teknikal Malaysia Melaka for providing the research grant RAGS/2013/FKP/TK04/01/B00028 and PJP/2018/FKP(2A)/S01582.

\section{REFERENCES}

[1] Mallory GO, Hadju JB. Electroless Plating: Fundamentals and Applications. AESF, Orlando, Florida. 1990.

[2] Chang CS, Hou KH, Ger MD, Chung CK, Lin JF. Effects of annealing temperature on microstructure, surface roughness, mechanical and tribological properties of Ni$\mathrm{P}$ and Ni-P/SiC films. Surface \& Coatings Technology. 2016; 288: 135-143.

[3] Maleque MA, Radhi M, Rahman MM. Wear study of Mg-SiCp reinforcement aluminium metal matrix composite. Journal of Mechanical Engineering and Sciences. 2016; 10(1): 1758-1764. 
[4] Balaraju JN, Rajam KS. Electroless deposition of $\mathrm{Ni}-\mathrm{Cu}-\mathrm{P}, \mathrm{Ni}-\mathrm{W}-\mathrm{P}$ and $\mathrm{Ni}-\mathrm{W}-\mathrm{Cu}-$ P alloys. Surface \& Coatings Technology. 2005; 195: 154-161.

[5] Bayer AM, Becherer BA. ASM Metals Handbook Volume 16: Machining. Chapter: High-Speed Tool Steels. ASM International; $8^{\text {th }}$ Edition.

[6] Nava D, Dávalos CE, Martínez-Hernández A, Manríquez F, Meas Y, Ortega-Borges R, Pérez-Bueno JJ, Trejo G. Effects of Heat Treatment on the Tribological and Corrosion Properties of Electrodeposited Ni-P Alloys. International Journal of Electrochemical Science. 2013; 8: 2670-2681.

[7] Abou-El-Hossein K, Kops N. Investigation on the use of cutting temperature and tool wear in the turning of mild steel bars. Journal of Mechanical Engineering and Sciences. 2017; 11(4): 2289-4659.

[8] Mohd Sanusi Abdul Aziz, Bahrin Ikram Redzuwan, Muhammad Zaimi, Raja Izamshah, Mohd Shahir Kasim, Mohd Amran Md Ali, Akira Mizobuchi, Tohru Ishida. Mechanical Properties And Cutting Performance Of Electroless Ternary NiW-P Coated Cutting Tools. Jurnal Teknologi. 2017; 79:5-2: 101-104.

[9] ASTM G99-05(2010). Standard Test Method for Wear Testing with a Pin-on-Disk Apparatus. ASTM International, West Conshohocken, PA, 2010, www.astm.org.

[10] Abdul Aziz MA. Electroless Quaternary Ni-Co-Cu-P Deposition On Fe Substrate. Project Report. Universiti Teknikal Malaysia Melaka. 2015.

[11] Zaimi M, Azran MN, M. Khaizaki M. Alif, Aziz MSA, 'Azam MA, Kasim MS, Munawar RF, Abd Manaf ME. Electroless Ni-Co-Cu-P Alloy Deposition in Alkaline Hypophosphite Based Bath. Key Engineering Materials. 2016; 694: 151-154.

[12] Azran MN, Khaizaki M, Alif M, Zaimi M, 'Azam MA, Kasim MS, Abdul Aziz MS, Sahaya Anand TJ, Che Haron CH, Ghani JA. Electroless Quaternary Ni-Cu-Co-P Alloy Deposition Mechanism In Acidic Bath Using Cyclic Voltammetry Measurement. Jurnal Teknologi. 2017; 79:5-2: 7-13.

[13] Guo RH, Jiang SQ, Yuen CWM, Ng MCF. Effect of copper content on the properties of $\mathrm{Ni}-\mathrm{Cu}-\mathrm{P}$ plated polyester fabric. Journal of Applied Electrochemistry. 2009; 39: 907-912.

[14] Zaimi M, Noda K. Quaternary alloy of Ni-Zn-Cu-P from hypophosphite based electroless deposition method. ECS Transactions. 2013; 45(19): 3-16.

[15] Heshmati M, Seifzadeh D, Shoghi P, Gholizadeh-Gheshlaghi M. Duplex Ni-Zn-Cu$\mathrm{P} / \mathrm{Ni}$-P electroless coating on magnesium alloy via maleic acid pretreatment. Surface \& Coatings Technology. 2017; 328: 20-29.

[16] Chen CK, Feng HM, Lin HC, Hon MH. The effect of heat treatment on the microstructure of electroless $\mathrm{Ni}-\mathrm{P}$ coatings containing $\mathrm{SiC}$ particles. Thin Solid Films. 2002; 416: 31-37.

[17] Keong KG, Sha W, Malinov S. Crystallisation kinetics and phase transformation behavior of electroless nickel-phosphorous deposits with high phosphorous content. Journal of Alloys and Compounds. 2002; 334: 192-199.

[18] Ashassi-Sorkhabi H, Dolati H, Parvini-Ahmadi N, Manzoori J. Electroless deposition of $\mathrm{Ni}-\mathrm{Cu}-\mathrm{P}$ alloy and study of the influences of some parameters on the properties of deposits. Applied Surface Science. 2002; 185: 155-160.

[19] Ahmad A, Ghauri KM, Ali L, Noshahi AA, Farr JPG. Influence of Heat Treatment on the Autocatalytic Ni-P and Ni-Co-P Deposits. Pakistan Journal Of Engineering And Applied Sciences. 2013; 12: 20-26. 
[20] Mohamad Noor MNA. Tribological and Electrochemical Behaviour of Electroless Quaternary Nickel Alloy Deposition for Cutting Tools. Master Thesis. Universiti Teknikal Malaysia Melaka. 2018.

[21] Vashishtha N, Sapate SG, Bagde P, Rathod AB. Effect of heat treatment on friction and abrasive wear behaviour of WC- $12 \mathrm{Co}$ and $\mathrm{Cr}_{3} \mathrm{C}_{2}-25 \mathrm{NiCr}$ coatings. Tribology International. 2018; 118: 381-399.

[22] Nava D, Dávalos CE, Martínez-Hernández A, Manríquez F, Meas Y, Ortega-Borges R, Pérez-Bueno JJ, Trejo G. Effects of Heat Treatment on the Tribological and Corrosion Properties of Electrodeposited Ni-P Alloys. International Journal of Electrochemical Science. 2013; 8: 2670-2681. 